\title{
A Study on the Estimation of the Evacuation Behaviors of Tokyo City Residents in the Kanto Earthquake Fire
}

\author{
NISHINO TOMOAKI, TSUBURAYA SHIN-ICH, HIMOTO KEISUKE and TANAKA TAKEYOSHI \\ Disaster Prevention Research Institute, Kyoto University \\ Gokasho, Uji, Kyoto 611-0011, JAPAN
}

\begin{abstract}
It is expected that there will be a large number of residents evacuating in an urban fire following a major earthquake. It is essential to implement effective evacuation safety measures for maintaining residents' safety. We have been developing a model to estimate evacuation behaviors of city residents. The model has been applied to past urban fires such as the Hakodate City Fire in 1934 and the Sakata City Fire in 1976. The model is based on the potential theory. In this paper, the model was refined by incorporating the following sub-models: (1) a safety evaluation model which controls destination of evacuees by evaluating the safety of the evacuation route network; and (2) a stochastic route selection model of evacuees. In the new model, evacuees travel from a high potential point to a low potential point and select the route stochastically from candidate routes due to potential. Potential is what the danger potential and the safety potential are integrated. In this study, the evacuation behaviors of residents in the Kanto Earthquake Fire in 1923, a representative fire disaster in Japan, were simulated. The results were compared in terms of the number and location of fatalities, and the number of people evacuated to major refuges.
\end{abstract}

KEYWORDS: evacuation model of residents, an urban fire, simulation, the Kanto Earthquake

\section{NOMENCLATURE LISTING}

\begin{tabular}{|c|c|c|c|}
\hline A & area $\left(\mathrm{m}^{2}\right)$ & $\Delta T$ & temperature rise $(\mathrm{K})$ \\
\hline$b$ & half-width of a fire plume (m) & $t$ & time (min) \\
\hline 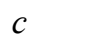 & specific heat (kJ/kgK) & $U$ & wind velocity (m/s) \\
\hline$C$ & constant due to hazard of a hot gas & $v$ & traveling velocity (m/s) \\
\hline & acceleration due to gravity $\left(\mathrm{N} / \mathrm{m}^{2}\right)$ & $W$ & width (m) \\
\hline$\Delta H_{b}$ & heat of combustion $(\mathrm{kJ} / \mathrm{kg})$ & $z$ & Height (m) \\
\hline I & amount of exposure to heat (Ks) & Greek & \\
\hline$k$ & density $\left(m^{-2}\right)$ & $\alpha$ & fire growth rate $\left(\mathrm{kW} / \mathrm{m}^{2} \mathrm{~s}^{2}\right)$ \\
\hline$L$ & length (m) & $\beta$ & the ratio of half-width \\
\hline$m_{b}$ & mass burning rate $(\mathrm{kg} / \mathrm{s})$ & $\varepsilon$ & potential conversion factor $\left(\mathrm{K}^{-1}\right)$ \\
\hline & constant due to hazard of a hot gas & $\rho$ & population density $\left(\mathrm{m}^{-2}\right)$ \\
\hline$P$ & probability & $\rho_{\infty}$ & air density $\left(\mathrm{kg} / \mathrm{m}^{3}\right)$ \\
\hline$Q$ & heat release rate $\left(\mathrm{kW} / \mathrm{m}^{2}\right)$ & $\Omega$ & dimensionless velocity \\
\hline & distance from the axis of plume (m) & $\theta$ & angle (radian) \\
\hline$T$ & temperature (K) & $\Phi$ & potential \\
\hline
\end{tabular}

\section{INTRODUCTION}

In Japan, fire is the second largest causes of disaster that causes numerous deaths and major earthquakes take place frequently, e.g. the Kanto Earthquake in 1923 and Kobe Earthquake in 1995. Numerous fatalities were caused by fire in the Kanto Earthquake, because institutions for fire prevention and fire control were not developed satisfactorily and numbers of wooden buildings were densely built. After that event, several approaches for fire prevention were taken, but buildings are not fully non-combustible. In the case of large earthquakes in which multiple fires may break out simultaneously, the spread of such fires may overwhelm the ability of firefighters and damage large areas. It was recognized again in the Kobe Earthquake that such a risk remains in a modern city.

It is predicted that major earthquakes will occur in future. It is essential to implement effective evacuation safety measures in order to maintain residents' safety following a major earthquake. It is essential to develop a model which estimates evacuation behaviors of residents in urban fires and to form clear relationships between an earthquake fire and evacuation of residents. We have been developing a model to 
estimate evacuation behaviors of city residents. The model has been applied to past urban fires such as the Hakodate City Fire in 1934 and the Sakata City Fire in 1976 [1,2]. The model is based on the potential theory. In this paper, the model was refined by incorporating the following sub-models: (1) a safety evaluation model which controls destination of evacuees by evaluating the safety of the evacuation route network; and (2) a stochastic route selection model of evacuees. In the new model, Evacuees travel from a high potential point to a low potential point and select the route stochastically from candidate routes due to potential. Potential is what the danger potential and the safety potential are integrated.

In this study, we selected the Kanto Earthquake Fire which is one of the representative fire disasters as a validation case and simulated evacuation behaviors of residents in Tokyo City.

\section{THE KANTO EARTHQUAKE}

The Kanto Earthquake occurred at 11:58 AM on September $1^{\text {st }}$ in 1923. Cities such as Tokyo City, Yokohama City and so on were damaged. Over 100,000 buildings collapsed and numbers of fires broke out at multiple locations. An outline of the effects of the Kanto Earthquake is shown in Table.1 [3,4,5]. The number of fatalities over the whole ruined area was 105,385 and in Tokyo City it was 68,660. The number of fatalities caused by fire in Tokyo City was 65,902. This study only deals with Tokyo City.

Table. 1: The Outline of The Kanto Earthquake

\begin{tabular}{l|l}
\hline The Date of Fire Breakout in Tokyo City & $11: 58 \mathrm{AM}, 1^{\text {st }}$, Sep, 1923 \\
\hline The Date of Fire Extinguishment in Tokyo City & $10: 00 \mathrm{AM}, 3^{\text {rd }}$, Sep, 1923 \\
\hline Number of Burnt Buildings & 293,387 \\
\hline \multirow{2}{*}{ Number of Fatalities } & 105,385 in the Ruined Area \\
& 68,660 in Tokyo City ( Fire : 65,902 Collapse : 2,758 ) \\
\hline Burnt Area in Tokyo City & $34,664,251 \mathrm{~m}^{2}$ \\
\hline Number of Afflicted People in Tokyo City & $1,356,595$ \\
\hline
\end{tabular}

The following factors are assumed to be major contributing factors to such a high number of fatalities: (1) city layout; (2) fire sources; (3) weather; (4) state of an evacuee; and (5) fire whirl. At that time, institutions for fire prevention and fire control were insufficient and most of wooden buildings were densely built. Due to city layout problems, the fire ignited and spread easily. As the earthquake struck the city area just before noon, fires for cooking were present which caused multiple ignitions. In terms of weather, the wind velocity was large due to a cyclone northwest of Tokyo City. This accelerated the rate of fire spread. By the strong wind, many huge fire plumes were blown down and covered the downwind area. As most of the evacuees traveled with their belongings such as furniture or household goods, roads and refuges were crowded. As fires approached the evacuees, the furniture and household goods ignited in sequence which augmented the damage. Fire whirls were observed at several points in Tokyo City and these killed a number of people. The damage in Hihukusyo Ato was crucial in that about 38,000 evacuees out of 40,000 who had evacuated died.

\section{THE EVACUATION BEHAVIOR MODEL}

The conceptual diagram of the evacuation behavior model is shown in Fig.1. The evacuation behavior model used in this study is based on the potential theory. The potential theory means that the direction of evacuee's travel is governed due to the gradient of the potential field where several factors that affect evacuation behaviors are distributed changing due to time. This model has the following features:

- Evacuation behavior of each person is calculated.

- Evacuees travel on the evacuation route network which consists of nodes and links. A link is the only route that an evacuee can pass, and a node is a point connecting several links. In an urban area, a link corresponds to an urban road and a node corresponds to an intersection.

- Influences on evacuation behavior due to fire plumes and thermal radiation from fire sources are quantitatively evaluated.

- $\quad$ Resident’s psychological orientation to a refuge recognized as safety is considered. 
- Evacuation behavior due to the hazard of urban area is considered without explicitly-setting evacuee's destination and egress route.

This model consists of the following models: (1) a hazard evaluation model of spreading fire (the danger potential model); (2) a safety evaluation model for evacuees (the safety potential model); and (3) a traveling model of residents.

In the hazard evaluation model of spreading fire, temperature rise due to fire plumes and thermal radiation from burning areas is evaluated as the danger potential $\Phi_{\text {danger }}$. An urban area is divided into lattice-shaped meshes and burning state of each mesh is estimated from the survey data of the fire. Temperature rise $\Delta T$ of each downwind mesh due to fire plumes and thermal radiation from burning areas is calculated and is converted proportionally to the danger potential $\Phi_{\text {danger }}$. In the safety evaluation model for evacuees, safety of an urban area recognized by residents is evaluated as the safety potential $\Phi_{\text {saferty }}$. In the safety potential model, an urban area is dealt as an evacuation route network. The destination of an evacuee is controlled by the safety potential $\Phi_{\text {safety }}$. These evaluated potentials, $\Phi_{\text {danger }}$ and $\Phi_{\text {safery }}$, are integrated into another potential $\Phi_{\text {overal }}$ given as equation (1), and the potential field distributed in an objective area is evaluated.

$\Phi_{\text {overall }}=\Phi_{\text {danger }}+\Phi_{\text {safety }}$

Potential $\Phi_{\text {overall }}$ means overall risk which an arbitrary point in urban area has, and is what both the risk due to fire plumes and thermal radiation and the safety recognized by residents are integrated.

In the traveling model of residents, evacuees travel on the evacuation route network. An evacuee travels from a high potential point to a low potential point selecting the link due to the gradient of potential $\Phi_{\text {overall }}$, and evacuee's evacuation is completed as reaching the destination. As an evacuee is exposed to fire plumes and thermal radiation from heat source during evacuation, the start and end of an evacuation are calculated on the basis of the amount of exposure to heat of an evacuee calculated from temperature rise $\Delta T$ of a mesh, and its critical amount. The following sections describe the evaluation of the danger potential $\Phi_{\text {danger }}$, the evaluation of the safety potential $\Phi_{\text {safety }}$, and the determination of evacuation behaviors respectively.

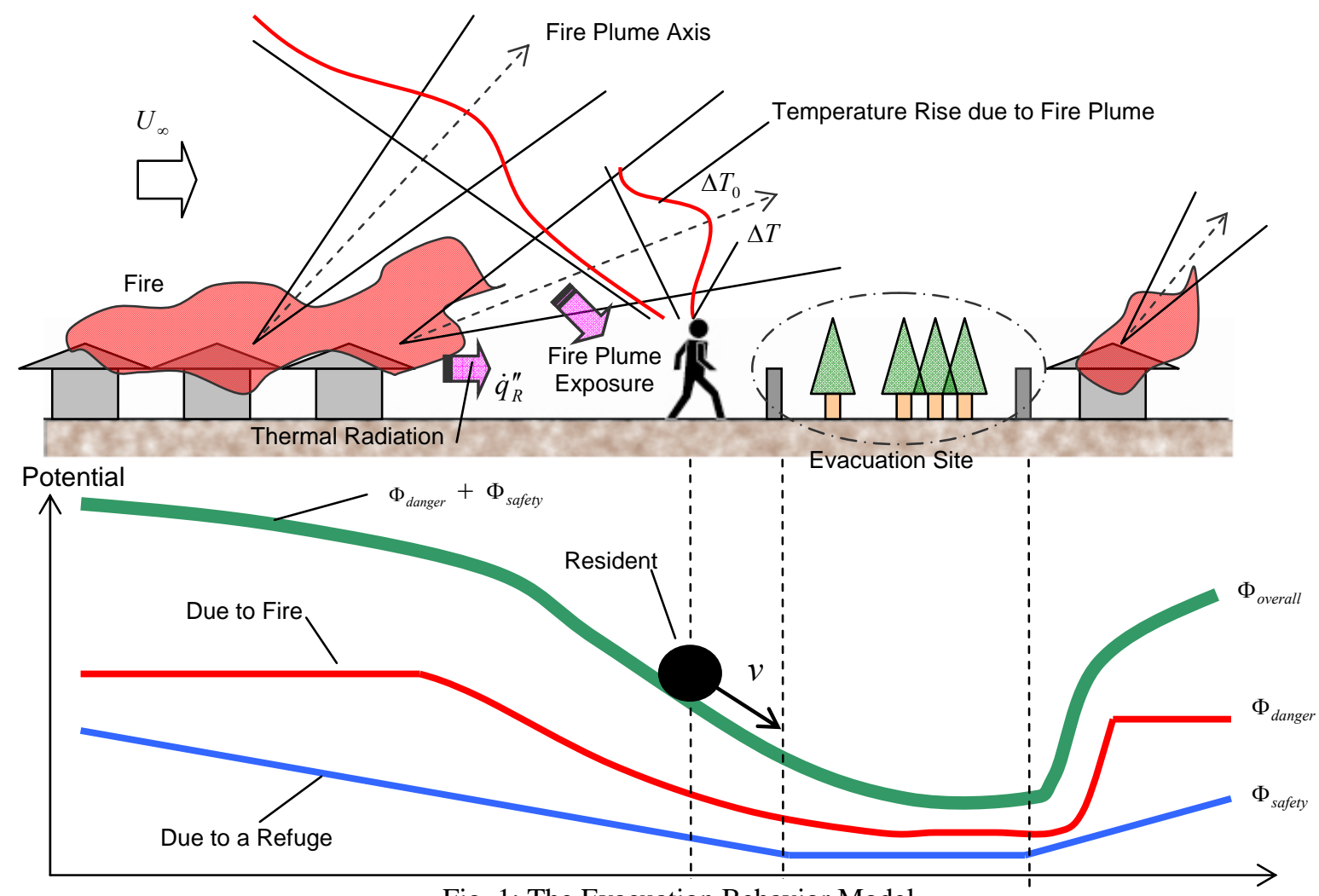

Fig. 1: The Evacuation Behavior Model 


\section{THE HAZARD EVALUATION MODEL OF SPREADING FIRE}

In the hazard evaluation model, temperature rise $\Delta T$ of meshes other than burning area is calculated and is converted to the danger potential $\Phi_{\text {danger }}$ as follows:

$\Phi_{\text {danger }}=\varepsilon \cdot \Delta T$

where $\varepsilon$ is potential conversion factor.

\section{Heat Release Rate of a Mesh}

For calculating the downwind temperature rise due to fire plumes, it is essential to estimate the burning state of meshes corresponding to heat sources. The onset time of the burning of a mesh is determined by identifying the fire breakout time, burning time and fire spread direction from field survey data. The heat release rate model of a mesh is shown in Fig.2.

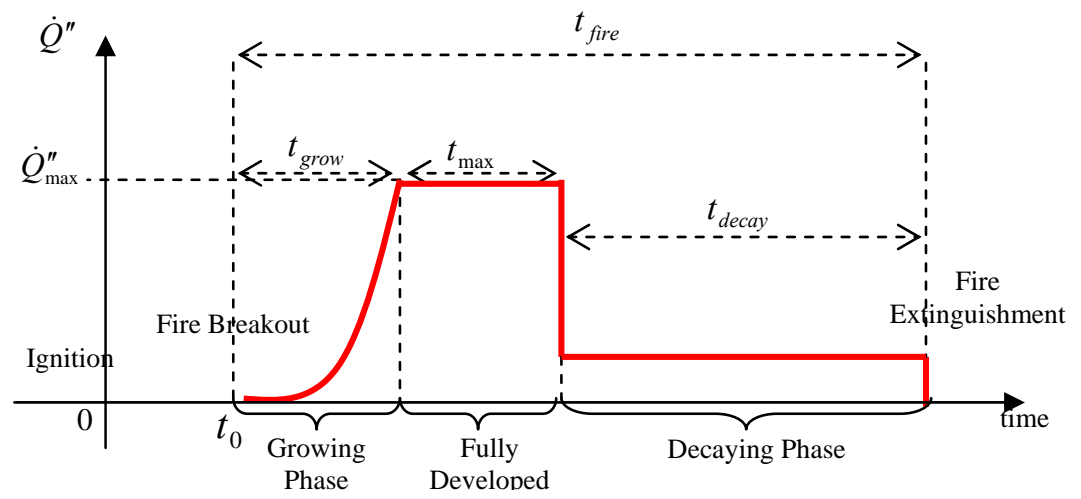

Fig. 2: Heat Release Rate Model

It is assumed that the extent of thermal radiation is restricted to meshes close to burning meshes. Heat transfer by radiation to the center of the mesh is evaluated and converted into a temperature rise. If the time exceeds the onset time of burning, then the mesh starts burning. It is assumed that the fire behavior of a mesh can be categorized into the following behaviors: (1) growing phase; (2) fully-developed phase; and (3) decaying phase. Heat release rate $\dot{Q}^{\prime \prime}(t)$ is given as:

$$
\dot{Q}^{\prime \prime}(t)= \begin{cases}\alpha\left(t-t_{0}\right)^{2} & \text { (Growing Phase) } \\ \Delta H_{b} \cdot \dot{m}_{b}^{\prime \prime} \cdot A_{\text {floor }} / A_{\text {city }}\left(=\dot{Q}_{\max }^{\prime \prime}\right) & \text { (Fully-Developed Phase) } \\ \dot{Q}^{\prime \prime}(1.0) & \text { (Decaying Phase) }\end{cases}
$$

where $\alpha$ is fire growth rate, $t_{0}$ is ignition time, $\Delta H_{b}$ is the heat of combustion of wood, $\dot{m}_{b}^{\prime \prime}$ is the mass burning rate per unit building floor-area, $A_{\text {floor }}$ is burnt floor-area of wooden buildings, $A_{\text {city }}$ is burnt urban area, $\dot{Q}_{\max }^{\prime \prime}$ is the maximum heat release rate of a mesh, $\dot{Q}^{\prime \prime}(1.0)$ is heat release rate after 1 minute of fire breakout in the growing phase.

In the growing phase, it is assumed that heat release rate is proportional to squared time $t^{2}$ as shown in equation (3). Therefore, the time $t_{\text {grow }}$ from fire breakout to when heat release rate is maximum is given as:

$t_{\text {grow }}=\left(\dot{Q}_{\max }^{\prime \prime} / \alpha\right)^{1 / 2}$

Based on the room temperature curve of a burning wooden building [8], it is assumed that the time of the fully-developed phase $t_{\max }$ is 5 minutes and the fire duration $t_{\text {fire }}$ is 30 minutes. It is assumed that heat 
release rate in the decaying phase $\dot{Q}_{\text {decay }}^{\prime \prime}$ equals that at 1 minute after fire breakout in the growing phase. The time $t_{\text {decay }}$ is the duration of the decaying phase.

\section{Temperature Rise due to Fire Plumes}

The temperature rise of a downwind mesh from burning meshes is calculated with the model shown in Fig.3. First, the individual temperature rises of a heat receiving mesh due to each fire plume are calculated. Next, these individual temperature rises are combined to give the temperature rise of a heat receiving mesh $\Delta T$ at a given time.

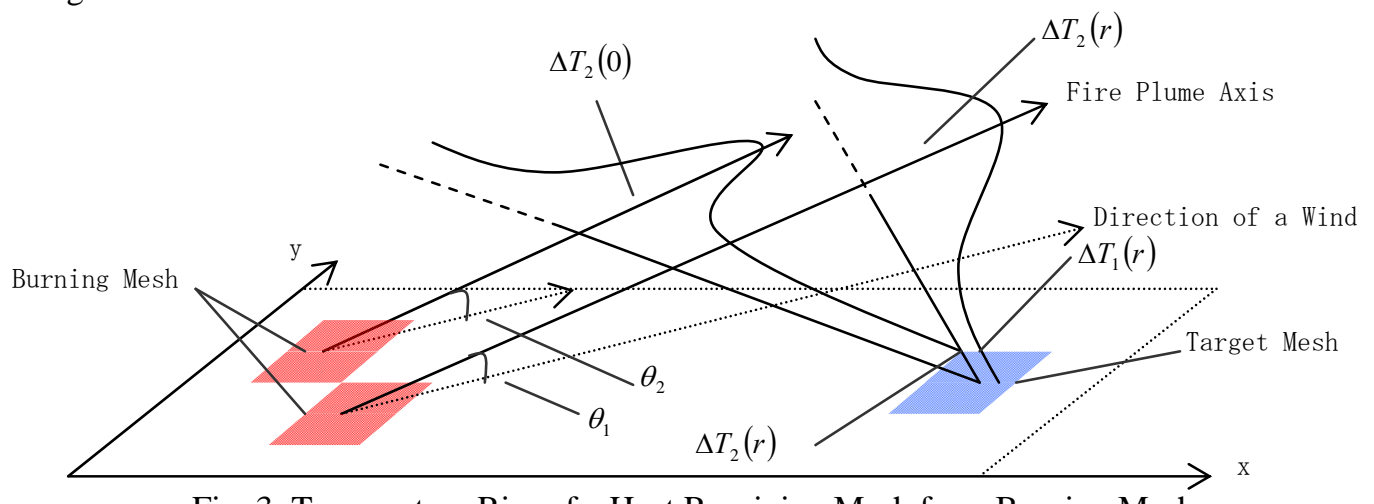

Fig. 3: Temperature Rise of a Heat Receiving Mesh from Burning Meshes

In this model, it is assumed that the temperature rise $\Delta T_{0}$ along the axis of fire plume from a fire source is approximated by that with finite size in calm environment as follows, not taking into account urban wind effect:

$$
\Delta T_{0}= \begin{cases}900 & \left(z / \dot{Q}^{2 / 5}<0.08\right) \\ 60\left(z / \dot{Q}^{2 / 5}\right)^{-1} & \left(0.08<z / \dot{Q}^{2 / 5}<0.2\right) \\ 24\left(z / \dot{Q}^{2 / 5}\right)^{-5 / 3} & \left(0.2<z / \dot{Q}^{2 / 5}\right)\end{cases}
$$

where $z$ is height from fire source on the plume axis, and $\dot{Q}$ is heat release rate of a burning mesh [7]. It is known that the temperature rise of a vertical fire plume shows approximately Gaussian distribution in horizontal direction, so it is assumed that the temperature rise $\Delta T(r)$ at the distance $r$ from the axis of windblown plume can be similarly given by the following equation.

$$
\frac{\Delta T(r)}{\Delta T_{0}}=\exp \left\{-\beta\left(\frac{r}{b}\right)^{2}\right\}
$$

where $b$ is the half-width of a fire plume, and $\beta$ is the ratio of half-width of temperature to that of flow velocity. The value of $b$ is approximated as $b=0.1 z$ and $\beta=0.9$ on the basis of the existing study on fire plume.

From the wind tunnel experiment by Yokoi [13], the gradient $\tan \theta$ of a wind-blown plume axis in case of a line fire source is given as:

$\tan \theta=0.1 \Omega^{-3 / 4}$

where $\Omega$ is the dimensionless velocity of the wind defined as: 
$\Omega=U_{\infty} /\left(\frac{Q_{1}^{\prime} g}{\rho_{\infty} c_{p} T_{\infty}}\right)^{1 / 3} \approx 3.3\left(U_{\infty} / Q_{1}^{1 / 3}\right)$

where $c_{p}$ is the constant-pressure specific heat, $\rho_{\infty}$ is the ambient air density, $T_{\infty}$ is the ambient temperature, $g$ is the acceleration due to gravity, and $U_{\infty}$ is the representative wind velocity.

A heat receiving mesh can be affected by multiple heat source meshes that are under burning. In this model, temperature rise $\Delta T$ of a mesh under this condition is calculated as follows:

$\Delta T=\left\{\sum_{i=1}^{N}\left(\Delta T_{i}\right)^{3 / 2}\right\}^{2 / 3}$

where $i$ is the identification mark of a burning mesh, and $N$ is the number of burning meshes [14].

\section{THE SAFETY EVALUATION MODEL FOR EVACUEES}

The safety potential $\Phi_{\text {safery }}$ is the safety of the evacuation route network recognized by residents, and controls destination of them. In this paper, it is assumed that the safety potential $\Phi_{\text {saferv }}$ is governed by how easily a resident can reach a refuge. Hence, the safety potential $\Phi_{\text {safety }}$ is governed due to the distance, the width, and the density of links from an arbitrary node to a refuge. Calculation of the safety potential $\Phi_{\text {safery }}$ is conducted on the evacuation route network. The following equation by analogy with Laplace equation is simultaneous for every node and is calculated by using Newton's law, so that the safety potential $\Phi_{\text {safery }}$ of each node is obtained.

$$
\begin{aligned}
& \sum_{j=1}^{m} w_{i, j} k_{i, j} \frac{\Phi_{\text {safety }, i}-\Phi_{\text {safety }, j}}{L_{i j}}=0 \quad(i: 1 \leq i \leq n) \\
& \Phi_{\text {safety }, E}=0, \quad \frac{\Phi_{\text {safety }, i}-\Phi_{\text {safety }, B}}{L_{i B}}=-1.0
\end{aligned}
$$

where $i$ is the number of a node, $j$ is the number of nodes connected with $i, E$ is the number of nodes of a refuge, $B$ is the number of boundary nodes of the area, $L$ is the distance between nodes, $w$ is the width of a link, $k$ is the density of a link. It is assumed that a refuge is the safest and the safety potential $\Phi_{\text {safer }, E}$ of it is zero corresponding to a standard value. The gradient condition for the safety potential is assumed to increase due to distance and increases by 1 for every 1 meter from a refuge.

\section{THE TRAVELING MODEL OF RESIDENTS}

The evacuation state of an evacuee is classified into the following state: (1) before evacuation; (2) evacuating; (3) evacuation completed; and (4) evacuation failed. It is assumed that residents hardly start an evacuation concurrently with the fire breakout, because evacuees get attached to their furniture and household goods. In this model, residents start to evacuate once they feel threatened by heat, and travel from a risky point to a refuge. During an evacuation, evacuees are exposed to heat due to fire plumes and thermal radiation. In this model, if evacuees can reach a refuge before the amount of exposure to heat of them reaches critical amount, they complete their evacuation. Conversely, if evacuees can not reach a refuge before that, they die.

\section{The travel Speed of Evacuees}

In this model, the travel speed in free ambulation is $1.3 \mathrm{~m} / \mathrm{s}$ as that of standard pedestrians in normal situation [7]. On the other hand, it is not assumed that in high-density crowd walking, pedestrians can not travel at all. Hence, in this model, the latest travel speed is $0.1 \mathrm{~m} / \mathrm{s}$, and the travel speed $v$ of evacuees is given as follows by population density $\rho$ of a link [15]: 


$$
v=\left\{\begin{array}{lc}
1.3 & (\rho<0.64) \\
1.48-0.28 \rho & (0.64 \leq \rho<5.3) \\
0.1 & (5.3 \leq \rho)
\end{array}\right.
$$

\section{The Stochastic Route Selection Model of Evacuees}

An evacuee selects the evacuation route stochastically from links connected with an evacuee's node as reaching a node. The probability that a link is selected is governed by the potential gradient between an evacuee's node and the connected node. The conceptual diagram of the stochastic route selection model of evacuees is shown in Fig.4. The potential of a node $\Phi_{\text {overal }}$ is given as equation (1). As an evacuee travels from an evacuee's node $i$ to the connected node $j$, the potential variation of a node per unit time due consideration of travel $\Delta \Phi_{i, j}$ is given as:

$$
\Delta \Phi_{i, j}=\frac{\Phi_{\text {overall }, i}-\Phi_{\text {overall }, j}}{L_{i, j}} \times v_{i, j}
$$

where $\Phi_{\text {overal }}$ is potential of a node, $L$ is the distance of a link connecting between evacuee's node $i$ and connected nodes $j$, and $v$ is the crowd travel speed of a link. As an evacuee travels from a high potential point to a low potential point, a link where $\Delta \Phi_{i, j}>0$ is fulfilled is selected by an evacuee. However, the probability that a route which causes an evacuee much safety is selected is higher, and the probability $P_{i, j}$ that a link connected a node $i$ with a node $j(1 \leqq j \leqq \mathrm{~m})$ is selected is defined as following equation.

$$
P_{i, j}= \begin{cases}0 & \left(\Delta \Phi_{i, j} \leq 0\right) \\ \frac{\Delta \Phi_{i, j}}{\sum_{k=1}^{m} \Delta \Phi_{i, k}} & \left(\Delta \Phi_{i, j}>0, \quad \Delta \Phi_{i, k}>0\right)\end{cases}
$$

Evacuees determine a route due to the potential of only connected nodes closed to an evacuee's node. The safety potential $\Phi_{\text {safety }}$ included in the potential $\Phi_{\text {overal }}$ is evaluated due to city layout over the whole area. Hence, an evacuee can consider geography information from the whole area, such as the location of refuges.

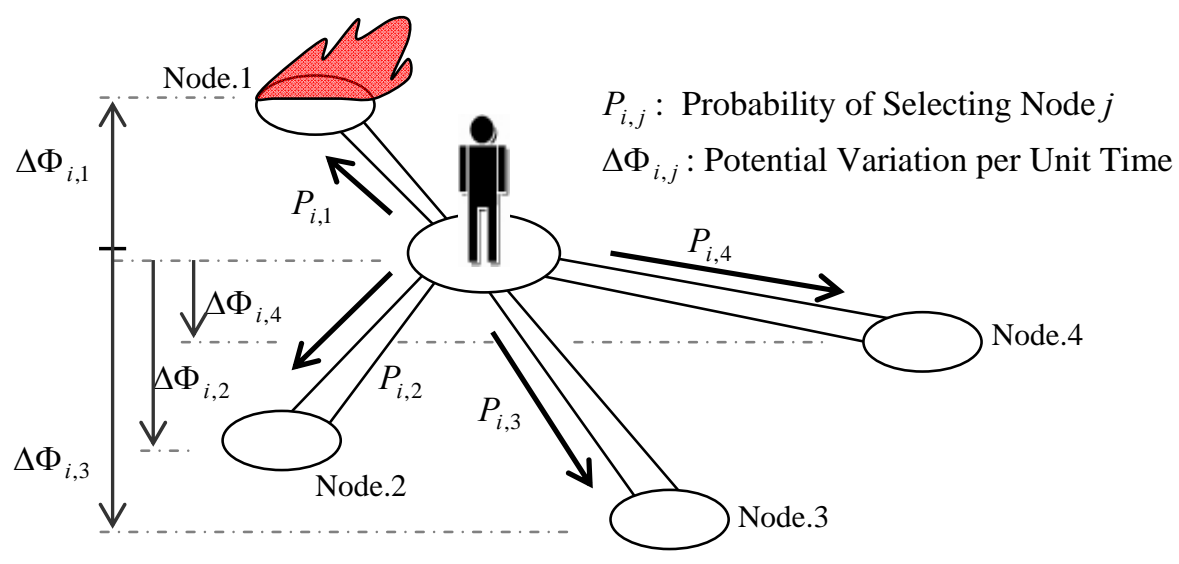

Fig. 4: The Stochastic Route Selection Model of Evacuees

\section{The Amount of Exposure to Heat and the Behavior of Evacuees}

During an evacuation, an evacuee is exposed to heat due to fire plumes and thermal radiation, and physically influence due to heat is accumulated. In the traveling model of residents, the start and end of an 
evacuation are governed by the amount of exposure to heat. It is calculated by using the temperature rise of a mesh calculated in the danger potential model. This calculation applies Haber's law [7]. Haber's law provides the relationship between exposure temperature $T$ and the time limit $t$ when a physiological reaction such as death arises. Hence, it is assumed that the amount of exposure to heat $I(t)$ is given as equation (14) and an evacuee dies as $I(t)$ reaches $C$.

$$
I(t)=\int_{t_{\text {satart }}}^{t}\left\{T(t)-T_{0}\right\}^{n} d t>C
$$

where $T(t)$ is temperature to which an evacuee is exposed, $T_{0}$ is critical temperature when physiological reaction arises, $t_{\text {start }}$ is the time when $T(t)$ exceeds $T_{0}$ for the first time, and $C$ and $n$ are constants governed by the hazardous property of a hot gas.

The transition of evacuation behavior due to the amount of exposure to heat is shown in Fig.5. Initially, a portion of residents starts to evacuate as $I(t)$ exceeds the earliest evacuation exposure level $I_{\text {early }}$. After that, all of residents start before $I(t)$ exceeds the latest evacuation exposure level $I_{\text {late }}$. Finally, an evacuee dies as $I(t)$ reaches the fatal dose $I_{\text {death }}$.

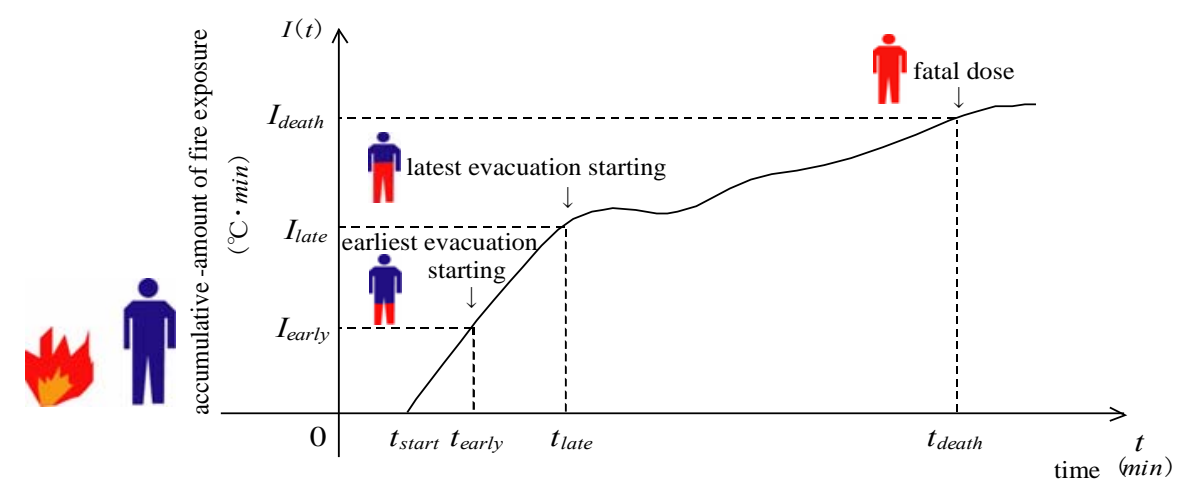

Fig. 5: The Transition of Evacuation Behavior due to the Amount of Exposure to Heat

\section{SIMULATION OF EVACUATION BEHAVIORS IN THE KANTO EARTHQUAKE FIRE}

In this study, we estimated evacuation behaviors of residents of Tokyo City in the Kanto Earthquake Fire by using the evacuation behavior model.

\section{Numerical Conditions}

Table. 2: Numerical Conditions

\begin{tabular}{|c|c|}
\hline Calculation Time & $43 \mathrm{hrs}$ \\
\hline Calculation Time Step & $1 \mathrm{~min}$ \\
\hline Mesh Width & $40 \mathrm{~m}$ \\
\hline $\begin{array}{c}\text { Number of Fire Origins } \\
\text { (Including Spotting Fires by } \\
\text { Firebrands) }\end{array}$ & 307 \\
\hline $\begin{array}{c}\text { Mass Burning Rate } \\
\text { Per Unit Building Floor-Area [11] }\end{array}$ & $0.1 \mathrm{~kg} / \mathrm{m}^{2} \mathrm{~s}$ ) \\
\hline Heat of Combustion of Wood & $16,000 \mathrm{~kJ} / \mathrm{kg}$ \\
\hline Fire Growth Rate & $0.02 \mathrm{~kW} / \mathrm{m}^{2} \mathrm{~s}^{2}$ \\
\hline $\begin{array}{c}\text { Critical Temperature Rise } \\
\text { of Physiologic Influence }\end{array}$ & $5 \mathrm{~K}$ \\
\hline Number of Resident Groups & 135,661 \\
\hline Number of Refuges & 9 \\
\hline
\end{tabular}

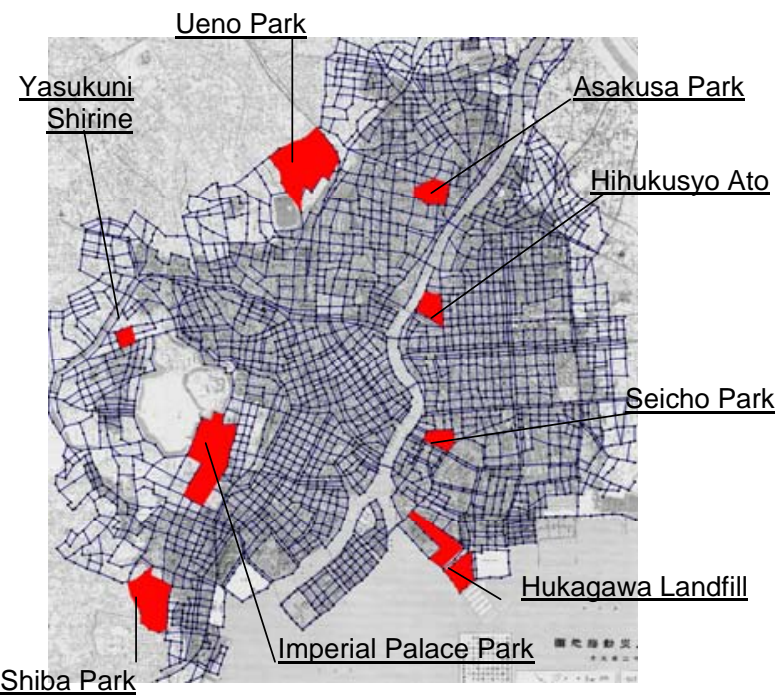

Fig .6: Assumed Evacuation Route Network and Refuges 
The conditions for calculation of evacuation behaviors of residents are shown in Table.2. Calculation time was $43 \mathrm{hrs}$ from the breakout and each calculation time step was $1 \mathrm{~min}$. The area was divided into $40 \mathrm{~m}$ wide meshes. In terms of the number of residents, 10 residents were collected into a minimum unit of computation. As a result, the number of resident groups was 135,661. Initial distribution of residents was set according to the demographic statistics [4]. The evacuation route network and the assumed refuge are shown in Fig.6. The maximum capacity of each refuge was set to the number of evacuated people reported in literatures $[3,4,9,10]$.

\section{Results and Discussion}

The results for 20hrs after the outbreak calculated by the evacuation behavior model are shown in Fig.7, since the number of residents at each evacuation state hardly changed after 20hrs after the outbreak.

Estimated ground-level temperature rises at 4 and 8 hrs after the breakout are shown in Fig.7. Average fire spread rate by $4 \mathrm{hrs}$ after fire breakout was $146 \mathrm{~m}^{2} / \mathrm{s}$. Such a high fire spread rate was brought about because the majority of buildings were wooden. The vast area of the city was covered by fire plumes, because the wind velocity was large. The area covered by wind blown fire plumes changed drastically due to the wind direction changes while the fire was spreading. Such large fire spread rate, large wind velocity, and rapid changes of the wind direction were the important factors for the devastating damage to residents.

The eventual number of residents at different evacuation states is shown in Table.3.

Table. 3: The Eventual Number of Residents at Different Evacuation State

\begin{tabular}{|c|c|c|c|c|}
\hline & Before Evacuation & Evacuating & $\begin{array}{c}\text { Evacuation } \\
\text { Completed }\end{array}$ & $\begin{array}{c}\text { Evacuation } \\
\text { Failed }\end{array}$ \\
\hline number & 41,330 & 4,640 & $1,159,580$ & 145,350 \\
\hline
\end{tabular}

As shown in Table.3, the eventual number of fatalities was 145,350. Whereas the number of fatalities reported in the literatures was 68,660.

Transition of the eventual number of residents at different evacuation state and that of the estimated burning area are also shown in Fig.7. The evacuation of residents was started almost concurrently with the breakout. As the fire spread rate was large and a vast area was covered with fire plumes, many of residents were urged to start evacuation immediately after fire breakout. The number of fatalities increased smoothly as time advances without a sudden increase at any particular time. From Fig.7, it can be seen that the fatalities occurred mainly within the first 9 hours after the outbreak. This seems reasonable given that the burning area reached its peak at 9 hours after fire breakout and started decreasing from then on.

In Table.4, the eventual number of residents at each refuge is compared with those of the survey reports in the literature. As shown in Table.4, the eventual number of residents at the refuges except Ueno Park, Imperial Palace Park and Yasukuni Shrine, were close to those of the survey reports. This indicates that the safety potential model lead numbers of residents to various refuges distributed across the wide area in spite of not explicitly-setting the evacuee's destination and egress route. From the results of their 3 refuges, the possibility that residents consciously traveled for a large familiar park, such as Ueno Park and Imperial Palace Park, is assumed. In the present model, the differences of resident orientation to a refuge and refuge visibility by residents are not considered. Thus, the relation between these factors and evacuation behaviors needs to be modeled. This may cause the simulation of more realistic evacuation behavior.

Table. 4: Eventual Number of Residents in the Refuges

\begin{tabular}{|c|c|c|c|c|c|c|c|c|}
\hline $\begin{array}{c}\text { Number of } \\
\text { Evacuated Person }\end{array}$ & $\begin{array}{c}\text { Ueno } \\
\text { Park }\end{array}$ & $\begin{array}{c}\text { Asakusa } \\
\text { Park }\end{array}$ & $\begin{array}{c}\text { Fukagawa } \\
\text { Landfill }\end{array}$ & $\begin{array}{c}\text { Hifukusyo } \\
\text { Ato }\end{array}$ & $\begin{array}{c}\text { Seicho } \\
\text { Park }\end{array}$ & $\begin{array}{c}\text { Imperial } \\
\text { Palace } \\
\text { Park }\end{array}$ & $\begin{array}{c}\text { Shiba } \\
\text { Park }\end{array}$ & $\begin{array}{c}\text { Yasukuni } \\
\text { Park }\end{array}$ \\
\hline Simulation & 174,100 & 70,880 & 52,020 & 40,290 & 20,010 & 215,430 & 56,020 & 26,660 \\
\hline Survey[3,4,9,10] & 500,000 & 70,000 & 50,000 & 40,000 & 20,000 & 300,000 & 50,000 & 50,000 \\
\hline Simulation/Survey & 0.3482 & 1.0125714 & 1.0404 & 1.00725 & 1.0005 & 0.7181 & 1.1204 & 0.5332 \\
\hline
\end{tabular}




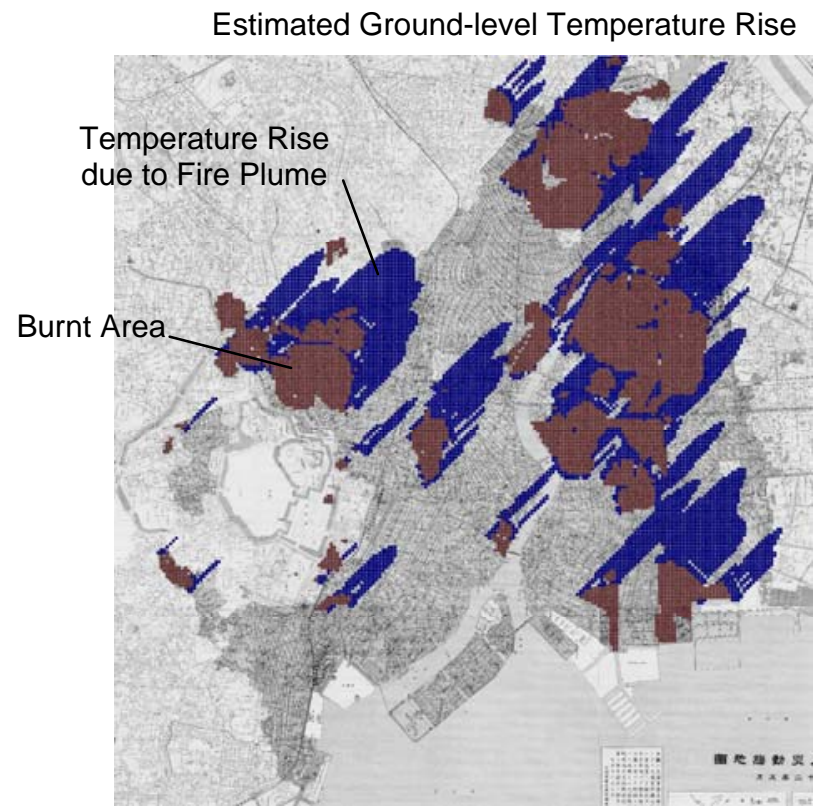

(a) 4 hrs after fire breakout

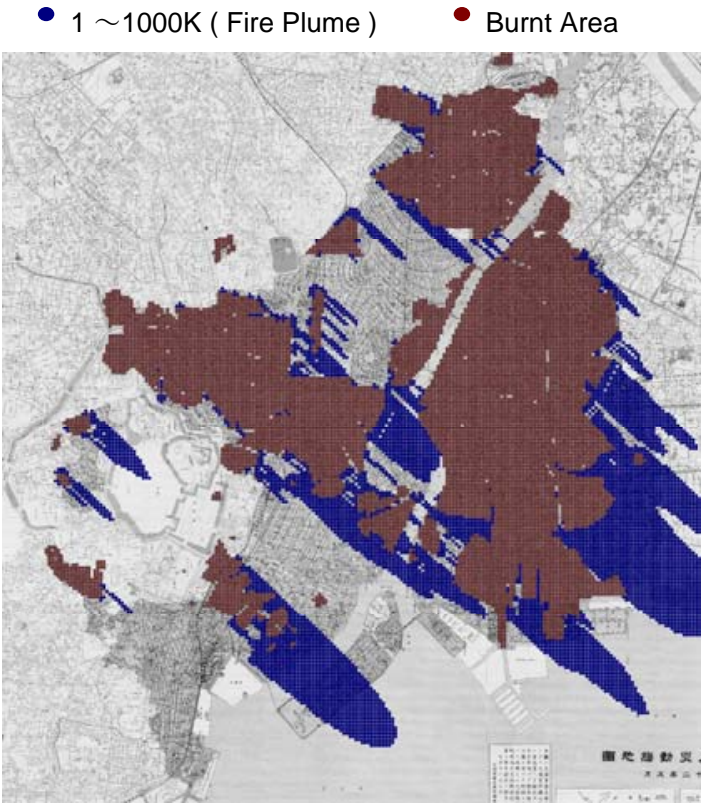

(b) 8 hrs after fire breakout

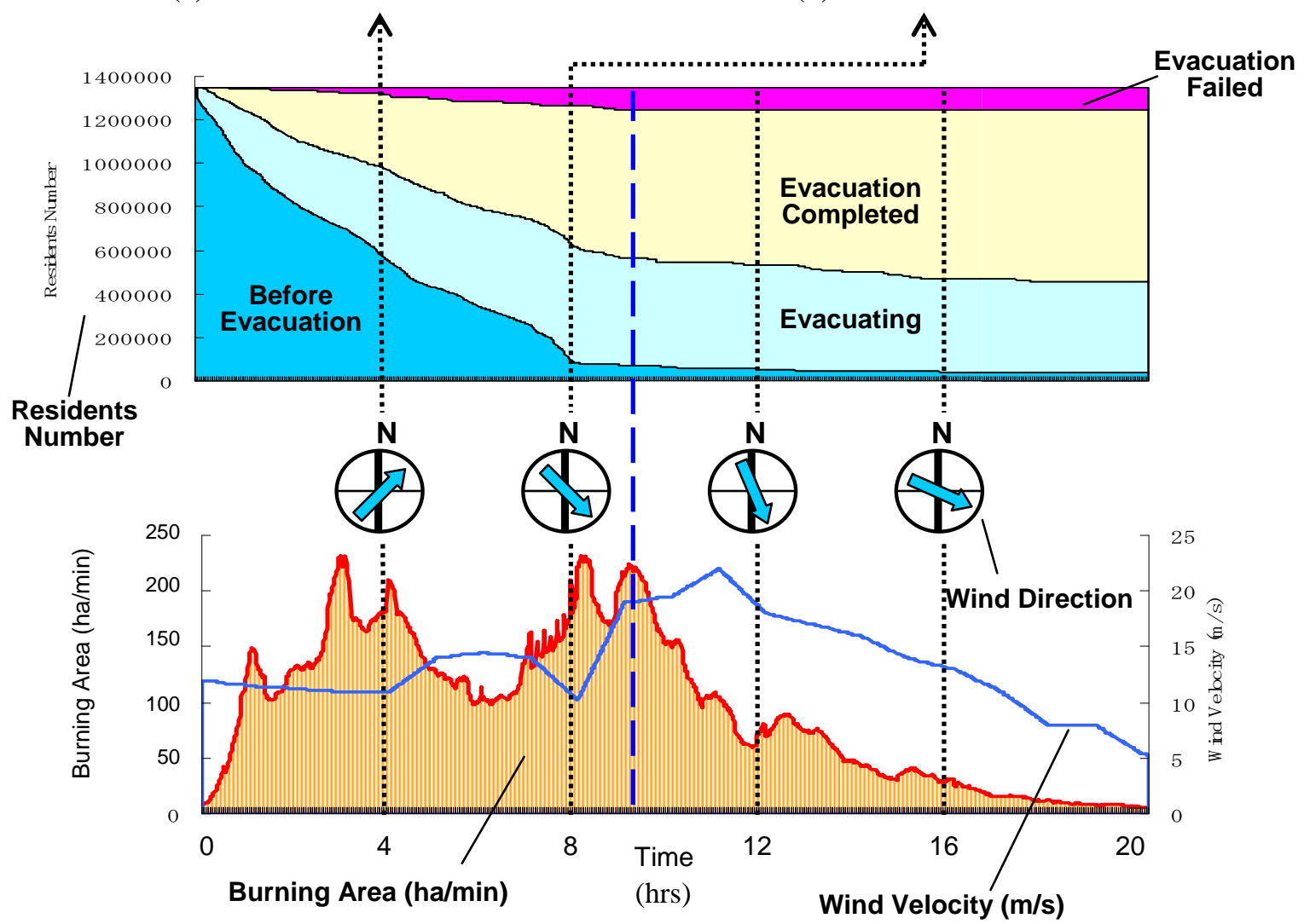

Fig. 7: The Results Calculated by the Evacuation Behavior Model

The distribution of fatalities in Tokyo City is shown in Fig.8, and those estimated by the model is shown in Fig.9. In these figures, the size of the circles corresponds to the number of fatalities. The distribution of fatalities estimated by the model was qualitatively similar to those in the Kanto Earthquake Fire as shown in the areas circled by a solid line. The distribution of fatalities in Honzyo and Hukagawa in the simulated 
result was especially similar to those in the fire. Many fatalities occurred in Hukagawa as there were few available egress routes due to a large number of water channels. In the other areas, there were discrepancies in the distributions of simulated and reported fatalities. In the simulated result, fatalities concentrated at a number of specific points such as the Shitaya area. The assumed contributing factors for these discrepancies are: (1) the limited reliability of the assumed evacuation route network which was modeled with a lack of historical data; and (2) the equality of the safety potential among all of the residents. In terms of the former, in the assumed evacuation route network, a larger number or a smaller number of links may be assumed by comparison with the city layout of that time. This may cause an increase or decrease in fatalities. In terms of the latter, as the safety potential was equivalent for all residents, evacuees still tended to select the same route as others in spite of the stochastic route selection. Evacuees selected a number of specific routes and fatalities were concentrated at these points.

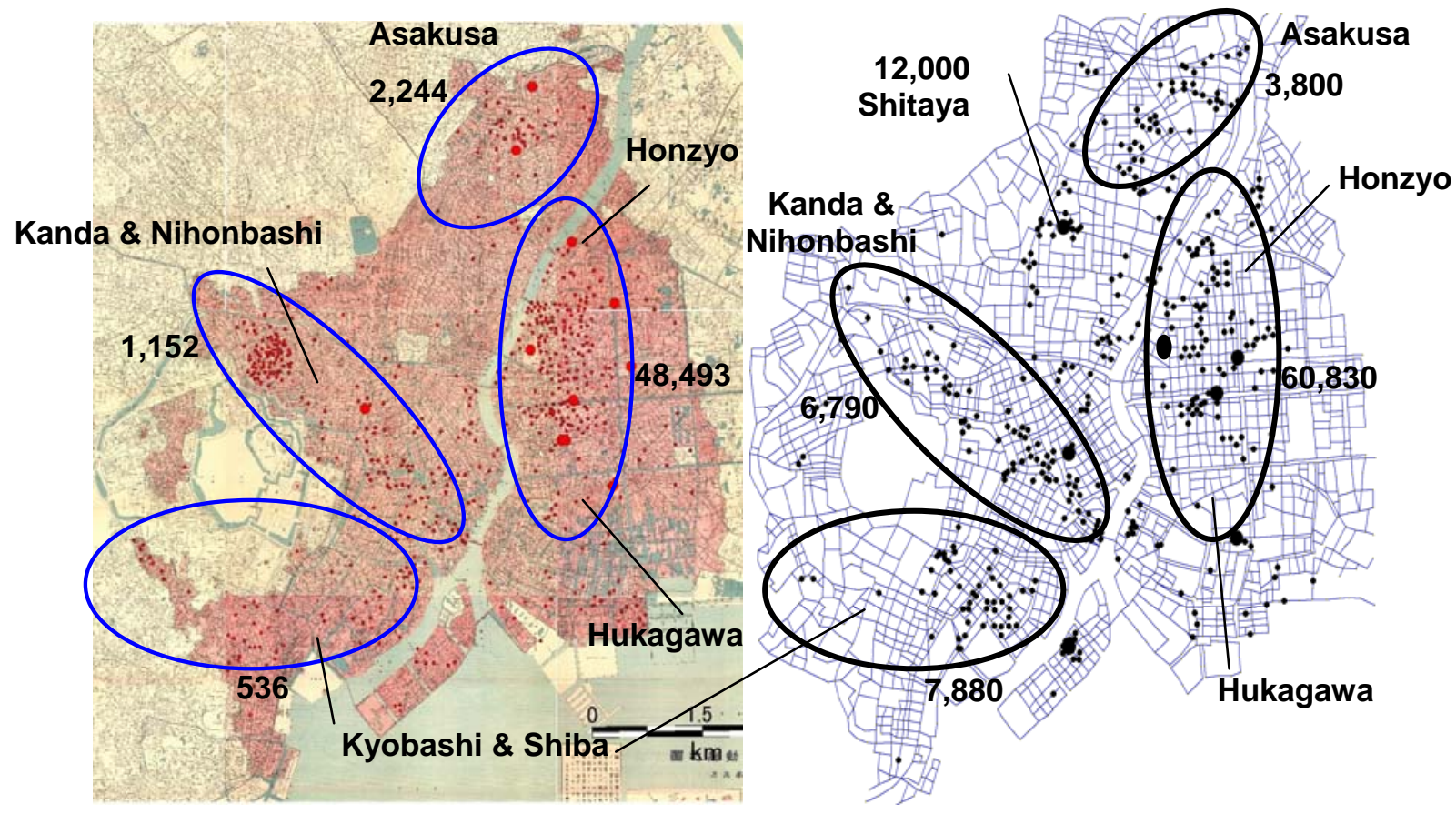

Fig. 8: Distribution of Fatalities in the Fire

Fig. 9: Distribution of Estimated Fatalities in Model

In the present model, the variation of resident characteristics due to age, gender and inhabited area, such as traveling velocity, acceptable level of exposure to heat, action area, and so on, is not considered. The influence on evacuation behavior by the interaction among evacuees is not considered. Hence, the model in consideration of these factors needs to be developed, and incorporation into the present model is needed. This may enable the estimation of more realistic evacuation behavior.

\section{CONCLUSIONS}

The evacuation behavior model for estimation of residents' evacuation behaviors in an urban fire is addressed. The model was applied to the Kanto Earthquake Fire and evacuation behaviors of residents in Tokyo City were simulated. The obtained results show that the model could simulate evacuation behaviors with reasonable accuracy especially in terms of temperature rise, and the number and transition of fatalities. However, there were some discrepancies in the eventual number of residents at refuges and the estimated distribution of fatalities. Additionally, in this model, influences on evacuation due to the smoke which lay low over a city, such as disorientation, changes of travel speed and so on, are not considered fully, and city structural damage due to an earthquake such as road block is not considered. Thus, there is room for improvement in the model. The model in consideration of resident different orientation to each refuge, evacuee's characteristics, the interaction among evacuees, and influences on evacuation due to smoke and structural damage of city by an earthquake, needs to be developed. However, judging from the results of its 
application to the Kanto Earthquake Fire, it is considered that the model is tending in the right direction, which is encouraging for further development.

Simulation using the evacuation behavior model requires existing field survey data of the fire spread in an urban area. On the assumption of an earthquake fire in the future, the fire spread can not be estimated. Hence, this model will be combined with a physically-based model for an urban fire spread [12]. In that model, fire spread within a building and among buildings is modeled based on physical knowledge. Hereby, evacuation behaviors of residents in a future earthquake fire can be simulated from the estimation of fire spread.

\section{REFERENCES}

[1] Nakao,M. and Tanaka,T., "Study on the Estimation of the Hazard to Evacuation Due to Windblown Fire Flow Induced by An urban fire”, Fire Safety Science - Proceedings of the 7th International Symposium, International Association for Fire Safety Science, 2002, pp.679-690

[2] Nasuno,A. and Tanaka,T., "Simulation Evacuation of Residents in the Hakodate Fire”, $7^{\text {th }}$ AsiaOceania Symposium, 2007

[3] Nakamura,S., "Record of the Kanto Earthquake”, Disaster Preventive Research Institute in Japan, 1925, pp 81-134

[4] The Metropolitan Police Department in Japan, “Report of the Kanto Earthquake”, 1925

[5] National Association Observatory of Japan, “Chronological Scientific Tables”, 2006

[6] Interior Ministry in Japan, "Pictures of the Kanto Earthquake”, 1926

[7] Tanaka,T., An Introduction to Building Fire Safety Science, The Building Center of Japan, 2001, pp 315-317

[8] Horiuchi, Saburo., Fire Prevention of a Building, Asakura, 1972, pp 48-49

[9] Yoshimura,A., Kanto Earthquake, Bunsyun, 2004

[10] The Study Group of the War of the Pacific, “The Kanto Earthquake” 2003

[11] Tanaka,T., "Research of the Estimation of Fire Spread at Real Time”, Report of the Prevention of Disasters Research Institute, 1999

[12] Himoto,K. and Tanaka,T., “A Physically-Based Model for An urban fire Spread”, Fire Safety Science - Proceedings of the 7th International Symposium, International Association for Fire Safety Science, 2002, pp.129-140

[13] Yokoi,S., "Temperature Distribution at the Leeward in Case of Liner Heat Source”, Collection of Theses of the Building Institute, No.46, Japan, 1965, pp.151-159

[14] Tsuchihashi,T., Tanaka,T., Tasaka,S. and Yoshida,M., "Estimation of the Rising Temperature at the Heated Points by the Fire Plume of Two Fire Sources", Epitome of the Building Institute, No.3007, Japan, 2000, pp.13-14

[15] Okada,M., Yoshida,K., Kashiwahara,S. and Tsuzi,M., Human Dynamics of a Building and a City, Kashima, 1977 